\title{
Effect of Pre-fermentation Maceration on the Content of Antioxidant Compounds in Grapevine Juice
}

\author{
Mojmir BARON, Michal KUMSTA, Bozena PRUSOVA*, \\ Lenka TOMASKOVA, Jiri SOCHOR
}

\author{
Mendel University in Brno, Faculty of Horticulture, Department of Viticulture and Enology, Valtická 337, CZ-691 44 Lednice, \\ CzechRepublic; MojmirBaron@seznam.cz;michal.kumsta@mendelu.cz;prusova.bozena@email.cz (*orrespondingauthor); \\ lenka.tomaskova@mendelu.cz; jiri.sochor@mendelu.cz
}

\begin{abstract}
Lower antioxidant capacity of white wines is caused by a lower content of phenolic compounds. In red wine, a higher content of phenolic compounds is the result of maceration. This study deals with effects of pre-fermentation maceration on contents of some selected compounds (above all antioxidants) in juices made of grapes of white varieties 'Welschriesling', 'Green Veltliner' and 'Neuburger'. The grapevine mush was macerated for 0; 2; 4; 8; 12; 24 and 48 hours. The spectrophotometry methods was used to estimate juice antioxidant activity and content of flavanols, anthocyans, catechins, hydroxycinnamic acids and flavonols. Contents of total titratable acids and $\mathrm{pH}$ were estimated as well. Results of this study show increasing tendency of all parameters with length of maceration. The highest content of antioxidants were found out in the variety 'Welschriesling'. Important are increasing values of hydroxycinnamic acids. However, the main role of the phenolics acids is to contribute to the anti-oxidant capacity, the tartaric esters of hydroxycinnamic acids (particularly caftaric acid) are centrally involved in oxidation and browning reactions in white wine. Their levels increased during the whole period of maceration. In 'Welschriesling', their content increased by $74 \mathrm{mg} \cdot \mathrm{L}^{-1}$. Decreasing tendency show results of titratable acids. Their contents decreased within the first 12 hours of maceration and thereafter they do not change. Longer must maceration could contribute to a decrease in contents of total titratable acids and, thus, to a better harmony of produced wine.
\end{abstract}

Keywords: hydroxycinnamic acids, juice browning, maceration, phenolics, white wines

\section{Introduction}

In the course of alcoholic fermentation, the process of maceration enables to extract phenolic compounds contained in solid parts of grapes. The maceration step, mostly used in technology of red wines, results in the extraction of phenolic substances and production of grape juices and wines rich in these compounds and showing strong antioxidant properties. This maceration step is the most important difference between technology of red and white wine (Paganga et al., 1999).

In red wine, a higher content of phenolic compounds is the result of maceration, in the course of which the phenolic compounds are released (i.e. extracted) from skins, seeds, stalks and pulp of berries (Fuhrman et al., 2001). The extraction of phenolic compounds is further supported by alcohol produced in the course of fermentation and by the increasing temperature. The maceration mostly does not take place in technology of white wines and for that reason the content of phenolic compounds of these wines are lower and they also show a lower antioxidant activity (Lamuela-Raventos and De la Torre-Boronat, 1999; Vinson and Hontz, 1995). The most frequently discussed problem is the increase in contents of phenolic substances, aromatic compounds and organic acids during maceration of white wines. An increase in the content of aromatic compounds is the most desirable phenomenon. Increased levels of phenolic substances are (more or less) not required, mainly due to the fact that they cause the occurrence of bitter, astringent and/or acrid tones in the final product (Peinado et al., 2004). At present, there is an intensive discussion concerning effects of maceration of white grapevine varieties on the quality of final products (Lamuela-Raventos and De la Torre-Boronat, 1999). On the other hand, the maceration of white grapevine varieties is more suitable for white grapevine varieties containing more acids because it shows a positive effect on the extraction of mineral substances (Ribéreau-Gayon et al., 2006).

The duration of the process of maceration (that is one of the most important mechanisms that control the release of these substances into the juice under conditions of a gentle crushing of grapes) is a matter of discussion. In white wine, phenolic substances occur above all as hydroxycinnamic acids that play a decisive antioxidant role prior to the onset of fermentation because they react with polyphenol oxidase and 
106

inhibit the process of juice browning (Hernanz et al., 2007). However, the phenolics acids contribute to the anti-oxidant capacity of both red and white wines, for example, the tartaric esters of hydroxycinnamic acids (particularly caftaric acid) are centrally involved in oxidation and browning reactions in white wine (Ribereau Gayon et al., 2006).

At present, there is an intensive discussion concerning effects of maceration of white grapevine varieties on the quality of final products (Lamuela-Raventos and De la Torre-Boronat, 1999).

The aim of this study was to map and describe which amounts of aforementioned substances were extracted and appeared in grapevine juice within different time intervals of maceration.

\section{Materials and Methods}

\section{Biologicalmaterial}

The experiment involved three grapevine varieties: 'Welschriesling', 'Green Veltliner' and 'Neuburger', vintage 2015. Grapes were crushed and destemmed in a stainless crusherdestemmer, macerated, and pressed. The mush was macerated for $0 ; 2 ; 4 ; 8 ; 12 ; 24$ and 48 hours.

Grapes used in the experimental part of this study originated from 20 years vineyards situated in the locality Velké Bílovice (wine-growing subregion of Velké Pavlovice). In this region, the average annual precipitations and temperature are $550 \mathrm{~mm}$ and $9.5^{\circ} \mathrm{C}$, respectively. In the soil of this region, content of clay is $20 \%$, content of free $\mathrm{Ca}$ is $12 \%$. Soil $\mathrm{pH}$ is in the range 6.1-6.9.

Rootstock 'CR2' typical for Czech Republic was used. The Czech grape training is modificated German training specially Rhone-Hessen, nevertheless fruitfull wood is horizontal tying. Clasps planting: $1 \times 1.2 \mathrm{~m}$. High of trunk is $0.75 \mathrm{~m}$. Berries were collected random from the top, middle, and bottom of selected clusters. In order to obtain representative sample, colored berries was not favored over greens. Berries were stored in sealed plastic bags in the refrigerator until processing.

\section{Estimation of antioxidant activity}

The determination procedure was described earlier (Sochor $e t$ al., 2010a). When doing this, a $150 \mu \mathrm{l}$ volume of the reagent (0.095 mM 2,2-diphenyl-1-picrylhydrazyl - $\mathrm{DPPH}^{\circ}$ ) was incubated with $15 \mu \mathrm{l}$ of wine sample. The absorbance was measured at $505 \mathrm{~nm}$ for 10 minutes. Results were converted to equivalents of gallic acid.

\section{Estimation of total flavanols}

Concentrations of total flavanols were estimated by means of method based on the reaction of juice with $p$ dimethylaminocinnamaldehyde (DMACA). The difference between this method and a widely used reaction with vanillin consists in the fact that in case of DMACA use there is no interference with anthocyans. Besides, it is also more sensitive and selective. A sample of $20 \mu \mathrm{l}$ wine was added into a $1.5 \mathrm{ml}$ Eppendorf micro test tube containing $980 \mu \mathrm{l}$ of the reagent $(0.1 \%$ DMACA and $300 \mathrm{mM} \mathrm{HCl}$ in $\mathrm{MeOH}$ ), vortexed and allowed to react at room temperature for 12 minutes. After this time interval, the absorbance value was measured at $640 \mathrm{~nm}$ and the result was compared with a blank sample. Using catechin as a standard (10-200 $\mathrm{mg}^{-1}$ ), concentrations of total flavanols were calculated from the calibration curve. Results are presented as catechin equivalents in $\mathrm{mg.L}^{-1}$ (Li et al., 1996).
Estimation of total contents of bydroxycinnamic acids and anthocyanins

These measurements were performed using well-established spectrophotometric methods (Zoecklein, 1990). The wine sample was placed into a $0.2 \mathrm{~cm}$ path-length quartz cuvette, Thereafter, $200 \mu \mathrm{l}$ of the sample and $1.8 \mathrm{ml}$ of 1.1 M HCL were added and the resulting solution was thoroughly mixed and kept for a period of 180 minutes at the room temperature.

A $0.22 \mathrm{M}$ solution of $\mathrm{K}_{2} \mathrm{~S}_{2} \mathrm{O}_{5}$ was used as a blank. When estimating anthocyanins, the absorbances were read at $320 \mathrm{~nm}$ $\left(\mathrm{A}_{320} \mathrm{HCl}\right)$ and at $520 \mathrm{~nm}\left(\mathrm{~A}_{520}^{\mathrm{HCl}}\right)$. Concentrations of total anthocyanins $\left(\mathrm{mg}^{-1} \mathrm{~L}^{-1}\right)$ were calculated as follows:

Total content of anthocyanins $\left(\mathrm{mg} \cdot \mathrm{L}^{-1}\right)=4 \times$ dilution $\times$ $/ \mathrm{A}_{520} \mathrm{HCl}_{-}(5 / 3) \times \mathrm{A}_{520} \mathrm{SO}^{\mathrm{SO}}$.

Total content of hydroxycinnamic acids $\left(\mathrm{mg}^{\mathrm{L}} \mathrm{L}^{-1}\right)=10 \times$ dilution $\times 12.387 \times \mathrm{A}_{320} \mathrm{HCl}$.

\section{Estimation of total flavanols and catechins}

Total flavanols were estimated using the $p$ dimethylaminocinnamaldehyde (DMACA) method (Li et al., 1996). As compared with a widely used vanillin method, a great advantage of this method is that there is no interference with anthocyanins. Furthermore, it provides a higher sensitivity and a better specificity. Wine sample $(20 \mu \mathrm{l})$ was poured into a $1.5 \mathrm{ml}$ Eppendorf micro test tube and $980 \mu \mathrm{l}$ of DMACA solution $(0.1 \%$ in $1 \mathrm{M} \mathrm{HCl}$ in $\mathrm{MeOH}$ ) was added. The mixture was vortexed and allowed to react at room temperature for $12 \mathrm{~min}$. The absorbances at $640 \mathrm{~nm}$ (flavanols) and at $360 \mathrm{~nm}$ (catechins) were then read against a blank sample prepared in a similar way but without DMACA. The concentration of total flavanols was then estimated from a calibration curve and constructed by plotting known solutions of catechin $\left(1-16 \mathrm{mg} \cdot \mathrm{L}^{-1}\right)$ against $\mathrm{A}_{640}\left(\mathrm{r}^{2}=\right.$ 0.998). Results were expressed as $\mathrm{mg} \cdot \mathrm{L}^{-1}$ of catechin equivalents.

\section{Estimation of $p H$}

Values of $\mathrm{pH}$ were estimated in non-diluted wine samples using a WTW pH-meter 526 in combination with the SenTix 21 $\mathrm{pH}$-electrode (manufacturer the WTW Company, Germany).

\section{Estimation of total titratable acids}

Contents of total titratable acids were estimated in an automatic titrator TITROLINE EASY (manufacturer SI Analytics $\mathrm{GmbH}$, Germany). A $0.1 \mathrm{~mol} \cdot \mathrm{L}^{-1}$ solution of $\mathrm{NaOH}$ was used as a titration reagent. For analyses, $10 \mathrm{ml}$ wine samples diluted with $10 \mathrm{ml}$ of distilled water was used. Individual samples were thereafter titrated up to $\mathrm{pH}$ 8.1. For the $\mathrm{pH}$ detection again the SenTix $21 \mathrm{pH}$-electrode was used. After the end of titration, the consumption of $\mathrm{NaOH}$ solution was read on the titrator display. This consumption was multiplied with the factor of $\mathrm{NaOH}$ solution used for the titration and with the coefficient 0.75 . The result of this multiplication was equal to the content of titratable acids in the wine sample $\left(\mathrm{mg} \cdot \mathrm{L}^{-1}\right)$.

\section{Statistical analyses}

Statistical analyses, tabular outputs and graphs were generated using programme packages Excel 2007 (manufacturer Microsoft Office, USA) and the statistical software Statistica 10 (Copyright (C) StatSoft).

Correlations existing between individual pairs of antioxidants are expressed as the Pearson's correlation coefficient and characterize the tightness of individual relationships. Values 
between 0.1 and 0.3 indicate a weak correlation while those between 0.4 and 0.6 and between 0.7-0.8 indicate medium and strong correlations, respectively. Values above 0.9 mean that the correlation is very strong. Significant correlations $(\mathrm{p}<0.05000)$.

\section{Results and Discussion}

\section{Estimation of antioxidant activity}

The antioxidant activity expresses the capability of the biological matrix (i.e. of the grapevine juice) to quench and/or trap free radicals. The most frequent methods of its estimation are methods of spectrophotometry. Advantages of these methods consist in their simplicity, good reproducibility, cheapness and, last but not least, unpretentiousness (as far as the human resources are concerned). The estimation of antioxidant activity by means of $\mathrm{DPPH}^{*}$ radicals represents one of the most frequent methods of this type (Sochor $e t$ al., 2010b).

Liang et al. (2014) studied phenolic profiles and antioxidant activities in 24 grapes of varieties of $V$. vinifera and observed a great variation in contents of total phenolic compounds (95.3-686.5 mg.100 g $\mathrm{g}^{-1}$ ) and flavonoids (94.7$\left.1,055.0 \mathrm{mg} \cdot 100 \mathrm{~g}^{-1}\right)$. They mentioned also great differences in antioxidant effects (the capacity to absorb oxygen radicals ranged from 378 to $3,386 \mathrm{mg}$ of Trolox equivalents in $100 \mathrm{~g}$. The total antioxidant activity was significantly correlated with levels of total phenolic substances and flavonoids. Must and red grapes showed much higher contents of photochemicals and antioxidant effects than table and white or yellow ones (Liang et al., 2014).

De la Cerda-Carrasco et al. (2014) mentioned that both the antioxidant activity and phenolic composition of wine were dependent on the differential extraction of chemical compounds from grapes during the process of wine making and that it was also critically associated with its quality (de la Cerda-Carrasco et al., 2015).

The antioxidant activity, as expressed by means of the DPPH equivalent, is presented in Fig. 1. Its increase in the course of maceration was observed in all three varieties under study. In 'Welschriesling' its initial and final (i.e. after 48 hours) values were $81.6 \mathrm{mg} \cdot \mathrm{L}^{-1}$ and $143 \mathrm{mg} \cdot \mathrm{L}^{-1}$, respectively. In 'Green Veltliner' and 'Neuburger', these increases were nearly identical (i.e. about $60 \mathrm{mg} \cdot \mathrm{L}^{-1}$ ) at the beginning of maceration and increased to $108 \mathrm{mg} \cdot \mathrm{L}^{-1}$ to its end.

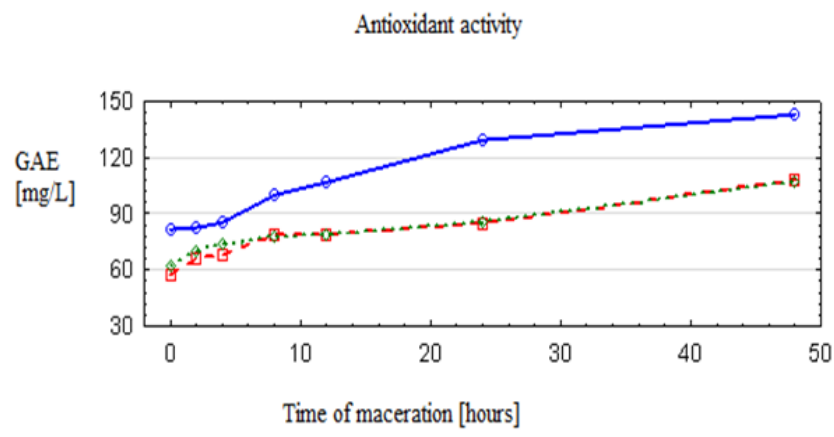

Fig. 1. Values of the antioxidant activity as determine with the DPPH test ('Welschriesling' - blue continuous line; 'Green Veltliner' - red dashed line; 'Neuburger' - green dotted line, GAE-gallic acid)

\section{Estimation offlavanols content}

Flavanols are those plant compounds, the name of which is derived from the Latin word flavus that means 'yellow'. The most important of them are catechin, epicatechin, gallocatechin, and epogallocatechin (da Silva et al., 2014).

In contents of flavanols, however, there were certain differences among these three varieties (Fig. 2). At the beginning of maceration, the lowest content of flavanols was observed in 'Green Veltliner' (21.3 mg.L $\left.\mathrm{L}^{-1}\right)$. After 48 hours it was more than doubled and reached the value of $50.6 \mathrm{mg} \cdot \mathrm{L}^{-1}$. The variety 'Neuburger' showed the highest initial level of flavanols $\left(32.5 \mathrm{mg} \cdot \mathrm{L}^{-1}\right)$. This value increased to as much as 60.6 $\mathrm{mg} \cdot \mathrm{L}^{-1}$; this was the second highest value recorded. Although the 'Welschriesling' began at the level of $26.3 \mathrm{mg} \cdot \mathrm{L}^{-1}$, it showed the highest dynamics and the value of DPPH was nearly tripled (to $76.7 \mathrm{mg}^{-1}$ ) after 48 hours of maceration.

\section{Estimation of the content of anthocyans}

Anthocyans are water-soluble pigments that belong to the group of flavonoids. Their colour is changing in dependence on $\mathrm{pH}$. Acid, neutral and alkaline solutions of anthocyans are usually red, violet and blue, respectively. They are present above all in skins of blue grapes. They are released from these skins in the course of maceration and cause the red coloration of wine. Anthocyanins readily polymerize with tannins; they also play an important role in tannin retention in and ageing of wine (Holton and Cornish, 1995; Prior et al., 1998).

Alvarez et al. (2006) studied the effect of pre-fermentation maceration of red grapes on contents of polyphenolic compounds, anthocyans and color intensity of wine and concluded that a prolonged maceration resulted in increased contents of these compounds in the fermented mush (Alvarez et al., 2006).

Ivanova-Petropulos et al. (2015) studied phenolic compounds in 22 samples of red wine originating from different wine-growing regions. All of them showed a relatively high content of total phenols and also a high antioxidant activity. When using HPLC, altogether 19 phenolic compounds were identified. Their contents were influenced above all by the variety and, to a smaller extent, also by yeasts and methods of fermentation. As compared with juices fermented using commercial (i.e. cultural) yeasts, especially the application of locally isolated (i.e. autochthonous) yeasts increased levels of anthocyans and phenolic acids (IvanovaPetropulos et al., 2015).

Contents of anthocyans are presented in Fig. 3. The lowest levels were found out in the variety 'Neuburger'; in this case the content of anthocyans $\left(1.4 \mathrm{mg} \cdot \mathrm{L}^{-1}\right)$ was not higher than in other two varieties even after 48 hours of maceration. In 'Welschriesling' and 'Green Veltliner', initial values were very similar (1.4 and $1.6 \mathrm{mg} \cdot \mathrm{L}^{-1}$, respectively) and a similar trend was observed also after 8 hours of maceration. After 48 hours, however, the highest level of anthocyans $\left(3.8 \mathrm{mg} \cdot \mathrm{L}^{-1}\right)$ was recorded in the variety 'Welschriesling'.

\section{Estimation of the content of catechins}

Catechins react with tannins to make the primary flavour component in red wine. They belong to the group of flavanols and their taste is tannic to bitter. In general, the smaller the catechin polymers, the stronger this sensation tends to be. The concentration of catechins in wine informs the winemaker 
Content of flavanols

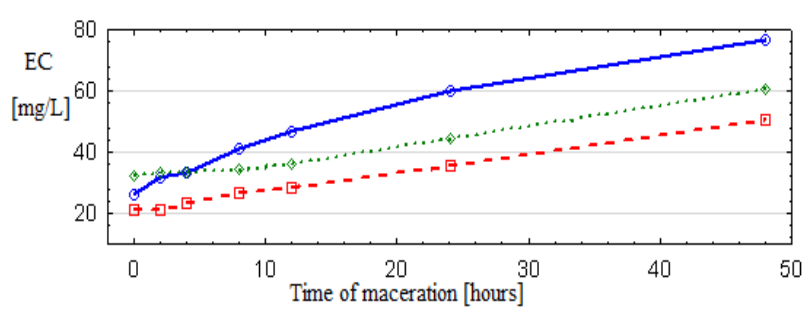

Fig. 2. Changes in contents of flavanols in the course of maceration ('Welschriesling'- blue continuous line, 'Green Veltliner' - red dashed line, 'Neuburger' - green dotted line, EC-catechinin equivalents)

about the intensity of extraction of these compounds from seeds (Arts et al., 2000).

Contents of catechins are illustrated in Fig. 4. After 48 hours, it was nearly doubled in all three varieties under study. In 'Welschriesling', the initial and final concentrations were 854.1 and 1,478.4 mg.L $\mathrm{L}^{-1}$, respectively while in 'Green Veltliner' and 'Neuburger' they were 645 and $1,109.8 \mathrm{mg} \cdot \mathrm{L}^{-1}$ and 679.3 and $1,028.2 \mathrm{mg} \cdot \mathrm{L}^{-1}$, respectively.

\section{Estimation of the content of hydroxycinnamic acid}

Hydroxycinnamic acids are classified as non-flavonoids. The group of hydroxycinnamic acids involves gallic acid, coumaric acid, caffeic acid, ferrulic acid, coutaric acid, caftaric acid and fertaric acid. In white wine, these are the most important phenolic compounds and participate in the determination of its color. They occur in the pulp of berries (Adams, 2006).

Hydroxycinnamic acids play a decisive antioxidant role prior to the onset of fermentation because they react with polyphenol oxidase and inhibit the process of juice browning (Hernanz et al., 2007). However, the main role of the phenolic acids is to contribute to the anti-oxidant capacity of both red and white wines. For example, the tartaric esters of hydroxycinnamic acids (particularly caftaric acid) are centrally involved in oxidation and browning reactions in white wine (Ribereau Gayon et al., 2006).

Contents of hydroxycinnamic acids are presented in Fig. 5. Their levels increased during the whole period of maceration. In 'Welschriesling', their content increased by $74 \mathrm{mg} \cdot \mathrm{L}^{-1}$ while in 'Green Veltliner' and 'Neuburger' they rose by 57 and $34 \mathrm{mg} \cdot \mathrm{L}^{-1}$, respectively.

Content of catechins

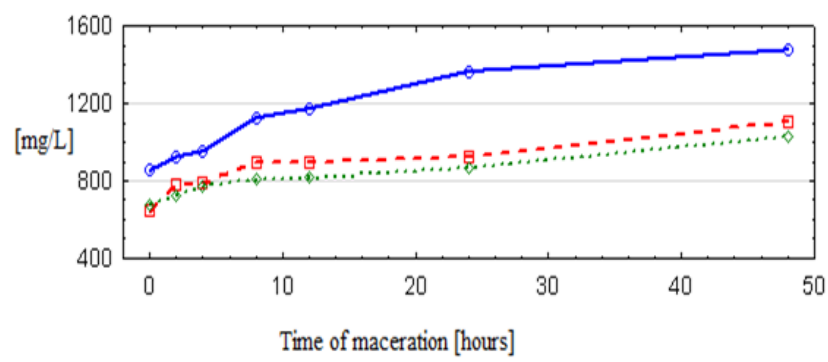

Fig. 4. Changes in contents of catechins in the course of maceration ('Welschriesling'- blue continuous line, 'Green Veltliner' - red dashed line, 'Neuburger' - green dotted line)

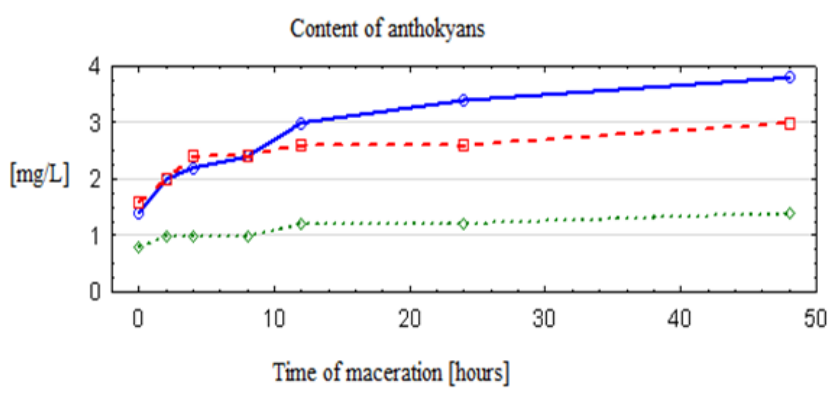

Fig. 3. Changes in contents of anthocyans in the course of maceration ('Welschriesling' - blue continuous line, 'Green Veltliner' - red dashed line, 'Neuburger' - green dotted line)

\section{Estimation of the content of flavonols}

Flavonols represent a group of secondary metabolites that involves many soluble phenolic compounds occurring in grapevine berries. These compounds play different physiological roles and for that reason they often participate in mechanism protecting plants against both biotic and abiotic stresses (Braidot et al., 2008). The most important flavonols are quercetin, myricetin, kaempferol, isorhamnetin and rutin. Flavonols are mostly strong antioxidants and show antiinflammatory effects (Kennedy et al., 2002).

Contents of flavonols increased relatively slowly (Fig.6). The initial and final values of the variety 'Neuburger' were 28.4 and $37.2 \mathrm{mg} \cdot \mathrm{L}^{-1}$, respectively. In the variety 'Green Veltliner', the corresponding values were 33.7 and $50.4 \mathrm{mg} \cdot \mathrm{L}^{-1}$. The highest levels found out in the variety 'Welschriesling' were 44.7 and $68.5 \mathrm{mg} \cdot \mathrm{L}^{-1}$, respectively.

\section{Estimation of $p H$ values}

It was found out that $\mathrm{pH}$ values were dependent on the rate of dissociation of acids, concentrations of free acids, and amounts of basic substances that were capable to bound hydrogen ions. This was an important parameter that enabled to determine the degree of ripeness of grapes. Its optimum fluctuates between 3.1 and 3.3. In case that $\mathrm{pH}$ value is higher than 3.5, the risk of a high activity of microorganisms is increased. This concerns above all different bacteria and wild yeasts. The susceptibility of juice and also of wine to show the presence of volatile acids, mousiness and other diseases and faults of wine is increased. At higher $\mathrm{pH}$ values the efficiency of sulphur dioxide decreases and the oxidation of both juice and wine is accelerated (Ribéreau-Gayon et al., 2006).

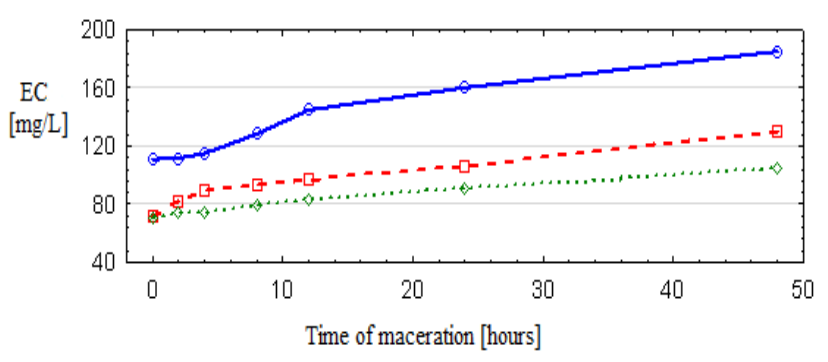

Fig. 5. Changes in contents of hydroxycinnamic acid in the course of maceration ('Welschriesling' - blue continuous line, 'Green Veltliner' - red dashed line, 'Neuburger' - green dotted line, EC-catechinin equivalents) 
Content of flavonols

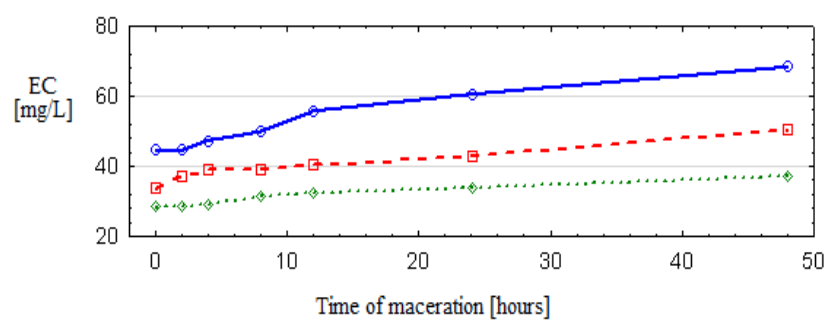

Fig. 6. Changes in contents of flavonols in the course of maceration ('Welschriesling' - blue continuous line, 'Green Veltliner' - red dashed line, 'Neuburger' - green dotted line, EC-catechinin equivalents)

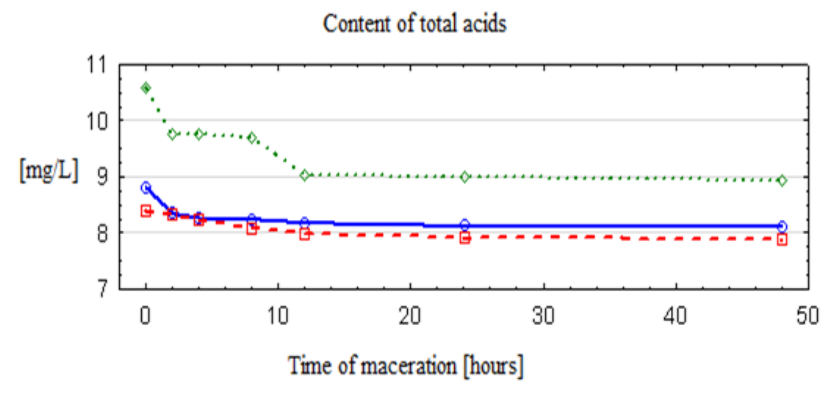

Fig. 8. Changes in contents of total acids in the course of maceration ('Welschriesling' - blue continuous line, 'Green Veltliner' - red dashed line, 'Neuburger' - green dotted line)

Values of $\mathrm{pH}$ are compared in Fig.7. This parameter increased only by tenths; in 'Welschriesling' it increased from 3.19 to 3.39, in 'Green Veltliner' from 3.11 to 3.25 and 'Neuburger' from 3.02 to 3.17 . It is also necessary to say that after 24 and 48 hours the values of $\mathrm{pH}$ were nearly the same and that their increase did not continued.

Estimation of the content of total titratable acids

Tartaric acid, lactic acid and smaller amounts of succinic acid, citric acid and acetic acid are the most important organic acids occurring in grapes. In grapes, the total content of acids usually ranges from 7 to $10 \mathrm{~g} \cdot \mathrm{L}^{-1}$.

The maceration of white grapevine varieties is more suitable for white grapevine varieties containing more acids because it shows a positive effect on the extraction of mineral substances (Ribéreau-Gayon et al., 2006).

Contents of titratable acids are presented in Fig. 8. In all varieties under study, contents of these acids decreased within the first 12 hours of maceration and thereafter they do not change. The highest initial content of acids was found out in the variety 'Neuburger', viz. $10.59 \mathrm{mg} \cdot \mathrm{L}^{-1}$ at the beginning 9.02 mg. $\mathrm{L}^{-1}$ after 12 hours and $8.95 \mathrm{mg} \cdot \mathrm{L}^{-1}$ after 48 hours. The juice of the variety 'Welschriesling' contained at the beginning of maceration $8.82 \mathrm{mg} \cdot \mathrm{L}^{-1}$; after 12 and $48 \mathrm{~h}$, these values were

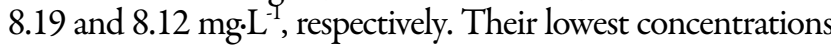
of total titratable acids were recorded in the variety 'Green Veltliner' (8.40 mg. $\mathrm{L}^{-1}$ at the beginning and $7.88 \mathrm{mg} \cdot \mathrm{L}^{-1}$ after 48h).

\section{Statistic evaluation}

Correlations existing between individual pairs of antioxidants are presented in Table 1 . In this table, significant

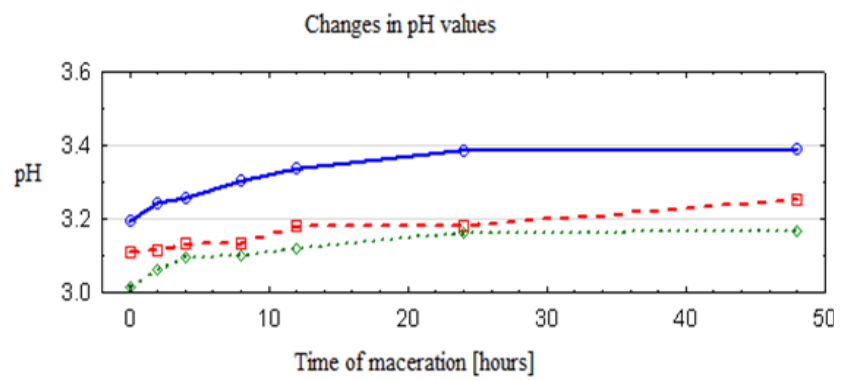

Fig. 7. Changes in $\mathrm{pH}$ values of $\mathrm{pH}$ in the course of maceration ('Welschriesling' - blue continuous line, 'Green Veltliner' - red dashed line, 'Neuburger' - green dotted line)

Table 1. Results of correlation analysis (A - time of maceration; B flavanols; C - antioxidant activity (DPPH); D - anthocyans; E catechins; F - hydrocinnamic acids; G - flavonols; $\mathrm{H}$ - pH; I - total acids)

\begin{tabular}{cccccccccc}
\hline & $\mathrm{A}$ & $\mathrm{B}$ & $\mathrm{C}$ & $\mathrm{D}$ & $\mathrm{E}$ & $\mathrm{F}$ & $\mathrm{G}$ & $\mathrm{H}$ & $\mathrm{I}$ \\
\hline $\mathrm{A}$ & 1 & 0.83 & 0.78 & 0.54 & 0.72 & 0.57 & 0.45 & 0.52 & -0.51 \\
$\mathrm{~B}$ & 0.83 & 1 & 0.85 & 0.32 & 0.73 & 0.60 & 0.42 & 0.54 & -0.17 \\
$\mathrm{C}$ & 0.78 & 0.85 & 1 & 0.61 & $\mathbf{0 . 9 5}$ & 0.90 & 0.78 & 0.86 & -0.48 \\
$\mathrm{D}$ & 0.54 & 0.32 & 0.61 & 1 & 0.77 & 0.81 & 0.89 & 0.82 & $\mathbf{- 0 . 9 4}$ \\
$\mathrm{E}$ & 0.72 & 0.73 & $\mathbf{0 . 9 5}$ & 0.77 & 1 & $\mathbf{0 . 9 6}$ & 0.89 & $\mathbf{0 . 9 3}$ & -0.65 \\
$\mathrm{~F}$ & 0.57 & 0.60 & $\mathbf{0 . 9 0}$ & 0.81 & $\mathbf{0 . 9 6}$ & 1 & $\mathbf{0 . 9 7}$ & $\mathbf{0 . 9 8}$ & -0.69 \\
$\mathrm{G}$ & 0.45 & 0.42 & 0.78 & 0.89 & 0.89 & $\mathbf{0 . 9 7}$ & 1 & $\mathbf{0 . 9 7}$ & -0.78 \\
$\mathrm{H}$ & 0.52 & 0.54 & 0.86 & 0.82 & $\mathbf{0 . 9 3}$ & 0.98 & 0.97 & 1 & -0.69 \\
\hline
\end{tabular}

The most significant correlations existed between hydrocinnamic acids and $\mathrm{pH}$ $(r=0.98)$, between flavonols and hydroxycinnamic acid $(r=0.97)$ and between flavonols and $\mathrm{pH}(\mathrm{r}=0.97)$. Significant correlations $(\mathrm{p}<0.05000)$

correlations are highlighted in bold. They are expressed as the Pearson's correlation coefficient and characterize the tightness of individual relationships. Values between 0.1 and 0.3 indicate a weak correlation while those between 0.4 and 0.6 and between $0.7-0.8$ indicate medium and strong correlations, respectively. Values above 0.9 mean that the correlation is very strong.

\section{Conclusions}

Previous studies observed content of phenolic compounds and antioxidation activity in red wines depending on the length of maceration. This study confirms the expected increasing of antioxidant activity, flavanols, anthocyans, catechins, hydroxycinnamic acids and flavonols in white varieties of wines. The most interesting fact is questionable quality of wine influenced undesirable increasing content of phenolic compounds in white wines. On the other hand, longer must maceration could contribute to a decreasing in contents of total titratable acids and, thus, to a better harmony of produced wine. This can be used in individual vintages with a lower $\mathrm{pH}$ of grapes (and with a high content of acids). The $\mathrm{pH}$ value and the "buffering capacity" of juice increases probably due to a release of potassium ions and $\mathrm{N}$-substances from the solid particles present in the mush; this thereafter resulted in a better harmony and more definite sensory character of produced wine. However, it is quite clear that an "ideal period of maceration " still remains to be the most important factor that influences properties of produced wine and its desirable sensory character. 
110

\section{Acknowledgements}

The financial support from sources of the project IGA $14 / 2014 / 595 \mathrm{ZF}$ is highly acknowledged.

\section{References}

Adams DO (2006). Phenolics and Ripening in Grape Berries. American Journal ofEnology and Viticulture 57(3):249-256.

Alvarez I, Aleixandre JL, Garcia MJ, Lizama V (2006). Impact of prefermentative maceration on the phenolic and volatile compounds in Monastrell red wines. Analytica Chimica Acta 563(1-2):109-115.

Arts ICW, van de Putte B, Hollman PCH (2000). Catechin Contents of Foods Commonly Consumed in The Netherlands. 2. Tea, Wine, Fruit Juices, and Chocolate Milk. Journal of Agricultural and Food Chemistry 48(5):1752-1757.

Braidot E, Zancani M, Petrussa E, Peresson C, Bertolini A, Patui S, Macri F, Vianello A (2008). Transport and accumulation of flavonoids in grapevine (Vitisvinifera L.). PlantSignaling \& Behavior 3(9):626-632.

da Silva CR, de Andrade Neto JB, et al. (2014). Synergistic effect of the flavonoid catechin, quercetin, or epigallocatechin gallate with fluconazole induces apoptosis in Candida tropicalis resistant to fluconazole. Antimicrob Agents Chemother 58(3): 1468-78.

de la Cerda-Carrasco A, López-Solís R, Nuñez-Kalasic H, Peña-Neira Á, Obreque-Slier E (2015). Phenolic composition and antioxidant capacity of pomaces from four grape varieties (Vitis vinifera L). Journal of the Science of Food and Agriculture 95(7):1521-1527.

Fuhrman B, Volkova N, Suraski A, Aviram M (2001). White wine with red wine-like properties: increased extraction of grape skin polyphenols improves the antioxidant capacity of the derived white wine. Journal of Agricultural and Food Chemistry 49(7):31643168.

Hernanz D, Recamales ÁF, González-Miret ML, Gómez-Míguez MJ, Vicario IM, Heredia FJ (2007). Phenolic composition of white wines with a prefermentative maceration at experimental and industrial scale. Journal of Food Engineering 80(1):327-335.

Holton TA, Cornish EC (1995). Genetics and biochemistry of anthocyanin biosynthesis. The Plant Cell7(7):1071-1083.

Ivanova-Petropulos V, Ricci A, Nedelkovski D, Dimovska V, Parpinello GP, Versari A (2015). Targeted analysis of bioactive phenolic compounds and antioxidant activity of Macedonian red wines. Food Chemistry 171:412-20.

Kennedy JA, Matthews MA, Waterhouse AL (2002). Effect of maturity and vine water status on grape skin and wine flavonoids. American Journal of Enology and Viticulture 53(4):268-274.

Lamuela-Raventos RM, De la Torre-Boronat MC (1999). Beneficial effects of white wines. Drugs under Experimental and Clinical Research 25(23):121-124.

Li YG, Tanner G, Larkin P (1996). The DMACA-HCl protocol and the threshold proanthocyanidin content for bloat safety in forage legumes. Journal of the Science of Food and Agriculture 70(1):89-101.

Liang Z, Cheng L, Zhong GY, Liu RH (2014). Antioxidant and antiproliferative activities of twenty-four Vitis vinifera grapes. PLoS One $9(8): \mathrm{e} 105146$.
Paganga G, Miller N, Rice-Evans CA (1999). The polyphenolic content of fruit and vegetables and their antioxidant activities. What does a serving constitute?. Free Radical Research 30(2):153-162.

Peinado RA, Moreno J, Bueno JE, Moreno JA, Mauricio JC (2004). Comparative study of aromatic compounds in two young white wines subjected to pre-fermentative cryomaceration. Food Chemistry 84(4):585-590.

Prior RL, Cao G, Martin A, SoficE, McEwen J, O'Brien C,... Mainland CM (1998). Antioxidant capacity as influenced by total phenolic and anthocyanin content, maturity, and variety of Vacinium species. Journal of Agricultural and Food Chemistry 46(7):2686-2693.

Ribéreau-Gayon P, Glories Y, Maujean A, Dubourdieu D (2006). Handbook of Enology (Vol 2). The Chemistry of Wine: Stabilization and Treatments $\left(2^{\text {nd }} \mathrm{Ed}\right)$. John Wiley \& Sons Ltd, The Atrium, Southern Gate, Chichester, West Sussex PO198SQ,England.

Sochor J, Ryvolova M, et al. (2010a). Fully Automated Spectrometric Protocols for Determination of Antioxidant Activity: Advantages and Disadvantages. Molecules 15(12):8618-8640.

Adams DO (2006). Phenolics and Ripening in Grape Berries. American Journal ofEnology and Viticulture 57(3):249-256.

Alvarez I, Aleixandre JL, Garcia MJ, Lizama V (2006). Impact of prefermentative maceration on the phenolic and volatile compounds in Monastrell red wines. Analytica Chimica Acta 563(1-2):109-115.

Arts ICW, van de Putte B, Hollman PCH (2000). Catechin Contents of Foods Commonly Consumed in The Netherlands. 2. Tea, Wine, Fruit Juices, and Chocolate Milk.Journal of Agricultural and Food Chemistry 48(5):1752-1757.

Braidot E, Zancani M, Petrussa E, Peresson C, Bertolini A, Patui S, Macrì F, Vianello A (2008). Transport and accumulation of flavonoids in grapevine (Vitisvinifera L). PlantSignaling \& Behavior 3(9):626-632.

da Silva CR, de Andrade Neto JB, et al. (2014). Synergistic effect of the flavonoid catechin, quercetin, or epigallocatechin gallate with fluconazole induces apoptosis in Candida tropicalis resistant to fluconazole. Antimicrob Agents Chemother 58(3): 1468-78.

de la Cerda-Carrasco A, López-Solís R, Nuñez-Kalasic H, Peña-Neira Á, Obreque-Slier E (2015). Phenolic composition and antioxidant capacity of pomaces from four grape varieties (Vitis vinifera $\mathrm{L}$ ). Journal of the Science of Food and Agriculture 95(7):1521-1527.

Fuhrman B, Volkova N, Suraski A, Aviram M (2001). White wine with red wine-like properties: increased extraction of grape skin polyphenols improves the antioxidant capacity of the derived white wine. Journal of Agricultural and Food Chemistry 49(7):31643168.

Hernanz D, Recamales ÁF, González-Miret ML, Gómez-Míguez MJ, Vicario IM, Heredia FJ (2007). Phenolic composition of white wines with a prefermentative maceration at experimental and industrial scale. Journal of Food Engineering 80(1):327-335.

Holton TA, Cornish EC (1995). Genetics and biochemistry of anthocyanin biosynthesis. The Plant Cell 7(7):1071-1083.

Ivanova-Petropulos V, Ricci A, NedelkovskiD, Dimovska V, Parpinello GP, Versari A (2015). Targeted analysis of bioactive phenolic compounds and antioxidant activity of Macedonian red wines. Food Chemistry 171:412-20. 
Kennedy JA, Matthews MA, Waterhouse AL (2002). Effect of maturity and vine water status on grape skin and wine flavonoids. American Journal of Enology and Viticulture 53(4):268-274.

Lamuela-Raventos RM, Dela Torre-Boronat MC (1999). Beneficial effects of white wines. Drugs under Experimental and Clinical Research 25(23):121-124.

Li YG, Tanner G, Larkin P (1996). The DMACA-HCl protocol and the threshold proanthocyanidin content for bloat safety in forage legumes. Journal of the Science of Food and Agriculture 70(1):89-101.

Liang Z, Cheng L, Zhong GY, Liu RH (2014). Antioxidant and antiproliferative activities of twenty-four Vitis viniffera grapes. PLoS One 9(8): e105146.

Paganga G, Miller N, Rice-Evans CA (1999). The polyphenolic content of fruit and vegetables and their antioxidant activities. What does a serving constitute?. Free Radical Research 30(2):153-162.

Peinado RA, Moreno J, Bueno JE, Moreno JA, Mauricio JC (2004). Comparative study of aromatic compounds in two young white wines subjected to pre-fermentative cryomaceration. Food Chemistry 84(4):585-590.

Prior RL, Cao G, Martin A, SoficE, McEwen J, O'Brien C,... Mainland CM (1998). Antioxidant capacity as influenced by total phenolic and anthocyanin content, maturity, and variety of Vacinium species. Journal of Agricultural and Food Chemistry 46(7):2686-2693.
Ribéreau-Gayon P, Glories Y, Maujean A, Dubourdieu D (2006). Handbook of Enology (Vol 2). The Chemistry of Wine: Stabilization and Treatments (2 $\left.2^{\text {nd }} \mathrm{Ed}\right)$. John Wiley \& Sons Ltd, The Atrium, Southern Gate, Chichester, West Sussex PO198SQ,England.

Sochor J, Ryvolova M, Krystofova O, Salas P, Hubalek J, Adam V, ... Provaznik I (2010). Fully automated spectrometric protocols for determination of antioxidant activity: Advantages and disadvantages. Molecules 15(12):8618-8640.

Sochor J, Salas P, Zehnalek J, Krska B, Adam V, Havel L, Kizek R (2010b). An assay for spectrometric determination of antioxidant activity of a biological extract. Listy Cukrovarnickea Reparske 126(11):416-417.

Vinson JA, Hontz BA (1995). Phenol Antioxidant index: comparative antioxidant effectiveness of red and white wines. Journal of Agricultural and Food Chemistry 43(2):401-403.

Zoecklein BW, Fugelsang KC, Gump BH, Nury FS (1990). Production wine analysis. Van Nostrand Reinhold Publication, New York pp 129168. 